A Constant Balancing Act: Delivering Sustainable University

Instructional Physical Activity Programs

Sheri J. Brock, ${ }^{1}$ Christina Beaudoin, ${ }^{2}$ Mark G. Urtel, ${ }^{3}$ Lisa L. Hicks, ${ }^{4}$ and Jared A. Russell ${ }^{1}$

${ }^{1}$ Auburn University, ${ }^{2}$ Grand Valley State University, ${ }^{3}$ Indiana University Purdue University Indianapolis, ${ }^{4}$ University of Indianapolis

\begin{abstract}
Author Note
Sheri J. Brock, Associate Professor in the School of Kinesiology at Auburn University.

Christina Beaudoin, Professor and Chair of the Department of Movement Science at Grand Valley State University.

Mark G. Urtel, Associate Professor and Chair of the Department of Kinesiology at Indiana University Purdue University Indianapolis (IUPUI).

Lisa L. Hicks, Professor and Chair of the Department of Kinesiology, Health and Sport Sciences at the University of Indianapolis.

Jared A. Russell, Professor and Assistant Director of the School of Kinesiology at Auburn University.

Correspondence concerning this article should be addressed to Sheri J. Brock, Ph.D., School of Kinesiology, Auburn University, brocksj@auburn.edu
\end{abstract}

This is the author's manuscript of the article published in final edited form as:

Brock, S. J., Beaudoin, C., Urtel, M. G., Hicks, L. L., \& Russell, J. A. (2020). A constant balancing act: Delivering sustainable university instructional physical activity programs. Kinesiology Review, 9(4), 293-298. https://doi.org/10.1123/kr.2020-0035 


\begin{abstract}
The goal of university instructional physical activity programs (IPAPs) is to provide quality instruction through best practices to encourage college students to lead healthy and physically active lifestyles. As IPAPs have continued to decline due to enrollment and budgetary concerns, the importance of quality and sustainability has become particularly paramount. Further, it is imperative to the existence of IPAPs that we strive to learn and share with each other in order to independently survive, but more essentially to flourish collectively as we are better together. In our varied experience, while some IPAPs face unique challenges, many obstacles are common, regardless of institution size and composition. This paper will offer the perspectives of four strikingly different colleges and universities in their quest to navigate challenges in delivery, maintain and support quality instruction, and advocate for IPAPs.
\end{abstract}

Keywords: support, teaching, advocacy, budget, quality, effectiveness 


\section{A Constant Balancing Act: Delivering Sustainable University Instructional Physical Activity Programs}

Many higher education institutions offer physical activity, fitness, and sport-based courses to college students, most commonly referred to as Instructional Physical Activity Programs (IPAPs). Often, students are attracted to IPAP courses for a myriad of reasons including personal health, skill development, social opportunities, stress reduction, boosting grade point averages, or to meet university-based credit requirements (Ansari et al., 2014; Baghurst, \& Kelley, 2014; Cardinal \& Kim, 2017; Cardinal et al., 2012; Crawford et al., 2007; Stapleton et al., 2017). As the motivation for enrolling in these courses varies from a student perspective, so too does the composition and success of IPAPs by institution. Many universities face uncertainty about the continuation and sustainability of IPAPs due to low enrollment, diminishing elective opportunities, and budgetary concerns (Cardinal et al., 2012; Cardinal, 2017). In fact, the number of colleges and universities requiring IPAP courses decreased from $67 \%$ in the mid-1990s to approximately 39\% in 2010 (Cardinal et al., 2012). In contrast, some universities have abundant enrollments with IPAPs as revenue generating game-changers (Brock et al., 2016). Regardless of the current state of affairs defined by institutions, one underlying commonality appears to be evident. All colleges and universities at some point in time, either historically or currently, have experienced the need to defend IPAPs when value and necessity have been called into question (Cardinal, 2017). It is important for IPAPs to be valued within colleges and universities, which necessitates critical examination of its role within the greater mission and vision of respective institutional contexts. While outlining the merits of IPAPs will likely create a proverbial "preaching to the choir" position, the intent of this paper is to collaboratively focus on the specific efforts of four institutions of drastically different 
compositions in their quest to maintain, further develop, and advocate for their IPAPs. First, a narrative of each institution is provided, followed by a collective discussion of challenges experienced in delivery of IPAPs. Additionally, strategies incorporated to support instructional effectiveness are presented, as well as suggestions for future advocacy and potential opportunities.

\section{Institution Descriptions}

In this section, the authors provide a description of the universities represented in this paper. The intent of the descriptions is to provide a frame of reference for the challenges and opportunities introduced, as experienced within IPAPs of varying sizes and resources.

Auburn University (AU) is a comprehensive, public land-grant institution with an approximate enrollment of 25,000 undergraduate and 5,000 graduate and professional students. Academic units are responsible for generating and managing revenues and expenditures under a Responsibility Centered Management (RCM) budget model. Auburn University's Physical Activity and Wellness Program (PAWP) is elective, grade-based, and housed within the School of Kinesiology, which offered 265 one and two credit hour course sections with an enrollment of 8,515 students in 2019-2020. A full-time administrative coordinator (1.0 FTE) oversees the program, assists with scheduling, and supervises approximately 40 graduate teaching assistants and 11 contract or specialty instructors, generating over 16,500 student credit hours (SCHs) annually. AU PAWP does not have shared facilities or equipment with other units on campus, and enrollment as related to the need for on-campus physical space includes $27 \%$ face-to-face (e.g., yoga, weight training, basketball); 36\% external sites (e.g., bowling, golf, CrossFit, scuba), and $37 \%$ distance education (e.g., Active Auburn, Wellness). 
Grand Valley State University (GVSU) is a master's degree-granting large comprehensive institution with an undergraduate enrollment of approximately 21,000 undergraduate students and 2,800 graduate students. Academic units operate under a centralized budgeting model. The instructional physical activity program (IPAP) offers a wide range of one credit elective fitness and sport-related courses. All courses are graded as credit/no credit. During 2019-2020, GVSA offered 181 sections generating 4,276 student credit hours (SCHs). The IPAP is located within the Movement Science Department and overseen by a program coordinator who is an administrative professional $(0.5 \mathrm{FTE})$ with teaching responsibilities in the department. The IPAP program coordinator oversees scheduling, staffing, and course development. All IPAP instructors (45-50) are HLC qualified (Higher Learning Commission) and the majority are parttime adjunct instructors. The IPAP program shares space, facilities, and some equipment with Campus Recreation and Athletics. In addition, GVSU offers off-campus courses (e.g., archery, bowling, sailing) and limited online courses (e.g., Fitness Walking).

IUPUI is a partnership between Indiana and Purdue universities. IUPUI is Indiana's premier urban research institute and a campus with an academic health science mission. IUPUI enrolls slightly over 20,000 undergraduate students and about 8,300 graduate students. Schools operate under a Responsibility Centered Management (RCM) model. The Department of Kinesiology hosts professional program courses for bachelor's, master's, and doctoral degrees, as well as general education and elective physical activity courses. The physical activity elective program is led by a $0.5 \mathrm{FTE}$ coordinator, generating approximately $1,547 \mathrm{SCH}$ per academic year, representing about $10 \%$ of the department's course portfolio. The program shares spaces with athletics and campus recreation. 
The University of Indianapolis (UIndy) is a private university located in Indianapolis, Indiana, offering associate, bachelor's, master's and doctoral degrees. Of the 6,000 students, approximately 1,500 are seeking graduate degrees. The university is categorized with the Carnegie classification of Doctoral/Professional University (D/PU) and operates under a centralized budget model. Physical activity courses are offered through the Department of Kinesiology, Health and Sport Sciences housed in the College of Health Sciences. The department is located in the health pavilion, a building dedicated to health and behavioral sciences, and shares facilities with the large university athletic department, which supports 23 athletic teams. The IPAP program consists of electives and a required wellness and fitness course for all undergraduate students. The IPAP courses are both elective credits to all students and required in a unique concentration, the Healthy Diploma ${ }^{\mathrm{TM}}$. IPAP courses comprise approximately $10 \%$ of the department offered credit hours and a general education coordinator (.21 FTE) oversees the development and delivery of the wellness and physical activity courses with a load reduction.

More detailed characteristics of these four IPAPs are presented in Table 1.

[insert Table 1]

\section{Challenges in Delivery of IPAP}

Currently, very little literature exists examining challenges to institutions/academic units concerning the delivery of IPAP curriculum (Cardinal et al., 2012; Russell, 2011). This section outlines five major challenges impacting IPAPs:

\section{Challenge \#1: Declining Student Enrollment Trends}

IPAPs at institutions of higher education are in decline and students have varied motivations when choosing to enroll in IPAP courses (Cardinal et al., 2012; Kim \& Cardinal, 
2019; Casebolt et al., 2015). Student degree programs (and financial aid guidelines) often limit the number of electives (Cardinal, 2017). This is a real issue for elective IPAPs, not part of the institution's academic core requirements (Cardinal et al., 2012). Additionally, students may prefer to utilize campus recreational facilities more often than IPAP courses, due to ease of scheduling or diverse course offerings (Casebolt et al., 2015; Kim \& Cardinal, 2019). Popular corporate franchises such as Planet Fitness or Gold's Gym are readily available schedule-wise and financially accessible for some students (Russell, 2011). IPAPs must stay vigilant regarding the potential of inclusion in core requirements, student needs, and innovative course offerings (Brock et al., 2016; Cardinal et al., 2012; Kim \& Cardinal, 2019).

\section{Challenge \#2: Identifying Qualified IPAP Instructors}

A major challenge is finding qualified instructors (e.g., graduate teaching assistants, adjunct instructors, faculty, coaches) to meet IPAP scheduling needs. Often graduate students may be readily available, but have limited instructional experience and require extensive training. Further, IPAPs often compete against campus recreational services or chain franchises for qualified personnel (Cardinal et al., 2012; Russell, 2011). Availability and compensation for qualified personnel can stretch the budgetary or scheduling limits of IPAPs (e.g., adjunct instructors requesting enrollment "guarantees" to pay fees or insurance associated with activities such as golf or kayaking). A secondary issue related to personnel is the IPAP coordinator/supervisor, who can serve in a limited capacity based on allocation (Russell, 2010). If part-time, competing responsibilities may limit availability and effectiveness to supervise and support IPAP instructors.

\section{Challenge \#3: Sharing Instructional Spaces, Facilities, and Equipment}


IPAPs often share athletic or recreational spaces with a number of other campus entities (Melton et al., 2016; Russell, 2010), which can limit course offerings due to availability. Entities include student organizations, community programs, recreation centers, or athletics. Courses requiring specialized instructional spaces (e.g., basketball, weight training, swimming) are especially limited when competing for facilities and equipment (Brock et al., 2018; Russell, 2010). Moreover, sufficient staff to set-up and break-down instructional areas (e.g., volleyball, badminton) can limit course offerings. Academic unit and IPAP administrators best serve their students when campus partners have clear articulation agreements regarding space and facility usage (Melton et al., 2016).

\section{Challenge \#4: Navigating Institutional Policies and Guidelines}

Institutional policies and guidelines impact how IPAP courses are delivered (Casebolt et al., 2015; Kim \& Cardinal, 2019). The institutional budget model utilized by administrators to allocate resources and make hiring decisions is paramount. Historically based budget models, predicated on centralized reallocation of revenue generated, do not incentivize academic units for creating innovative new courses to produce more SCHs, which leaves administrators unable to justify investment in IPAPs (Brock et al., 2016; Russell et al., 2014).

\section{Challenge \#5: Providing Quality IPAP Curriculum and Instruction}

Course quality is a concern of IPAPs and often is attributed to differences in instructors (Langdon \& Wittenberg, 2019; Melton et al., 2016). As mentioned previously, the level of expertise and training of available IPAP instructors can vary greatly, which is concerning considering the visibility of IPAPs across some campuses. A coordinator can be instrumental in providing oversight regarding quality and consistency, however supporting instructional endeavors can be limited with a partial IPAP allocation depending on the size of the program 
(Brock et al., 2018; Melton et al., 2016; Russell, 2010). Managing and supporting an instructional cohort is a major challenge to ensure instructors are equipped to deliver IPAP curriculum effectively (Langdon \& Wittenberg, 2019).

\section{Supporting Effective Instruction}

Supporting effective instruction remains a relatively understudied concept within higher education, particularly when considering part-time or adjunct faculty. The literature almost exclusively emphasizes assessing teaching effectiveness or experiences of part-time faculty within higher education (Kimmel \& Fairchild, 2017). Santisteban and Egues (2014) addressed the "cultivation" of adjunct faculty toward effective teaching yet, in a very narrow framework of Nursing Education focused on orientation and mentorship. Melton et al. (2016) addressed realities IPAP programs face when relying heavily on part-time adjuncts and graduate assistants as instructors to provide guidance to kinesiology administrators and coordinators. This holistic approach toward the onboarding process for part-time faculty extended the Santisteban and Eques (2014) model beyond orientation and mentorship, to include teaching development. Additionally, Brock et al. (2018) offered guidance and strategies for how Auburn University delivers its IPAP, revealing various large program issues and potential solutions. NASPE (2009) provided a comprehensive guide titled "The Appropriate Instructional Practice Guidelines for Higher Education Physical Activity Programs". This seminal piece started an evolving dialogue and advised, "Quality instruction in physical activity programs incorporates best practices, derived from both research and teaching experiences, into a pattern of instruction that maximizes opportunities for learning and success for all students" (p. 2). The message to IPAPs is essentially an expectation of intentional commitment to quality. 
Assigning effective instructors to IPAP courses is a yearly and seemingly ongoing cycle for academic units. At IUPUI, part-time instructors teach $64 \%$ of elective IPAP courses, with $34 \%$ taught by graduate students, and less than 3\% taught by full-time faculty. The essential objective is to find class coverage, however the importance of assigning the most qualified instructor to ensure a successful teaching and learning experience for everyone should not be overlooked. The economic reality of programming is a need to balance highly effective instruction with cost-effective instruction. Most administrators realize the key to keeping these courses staffed and taught effectively is to engage in the ongoing cycle of training, evaluation, and development. However, there are marked differences in striving to achieve effective instructional practices between part-time (adjunct) faculty and graduate students, as first reported by Melton et al. (2016).

For IUPUI, recruitment and hiring of part-time faculty and graduate students is the largest and most important part of supporting effective instructional practices. For part-time faculty, the process begins with advertising to bring in fairly camera-ready instructors who are business owners, have industry/teaching experience, are currently employed in the fitness or club industry, and/or hold appropriate professional achievements. Presenting a clear scope of work, with an explicit course description tends to set the proper stage for gauging interest and readiness of the prospective part-time faculty member. Alternatively, the department typically selects graduate students based on their expressed research interests and alignment with the mentoring graduate faculty; without regard to their ability to teach, as previously noted by Langdon and Wittenberg (2019). Therefore, campus orientations to teaching and in-house training are the key drivers for success in readying the graduate assistant for this new responsibility. 
Many resources to support effective instruction are readily available at IUPUI for both part-time faculty and graduate assistants. A prime campus resource is the Center for Teaching and Learning (CTL). Each part-time instructor is taken on a tour of the CTL, introduced to the front desk staff, and given a broad overview of how and why this center should be used. Giving a cursory mention is simply not enough, and it is well worth the effort to alleviate concerns and greatly reduce the fear of the unknown, especially with so much information coming at them quickly. For graduate students, significant landing spots are reinforced as previously visited on the campus-based orientation tour. IUPUI focuses on teaching all ability levels effectively with intentionally differentiated instruction to support the departmental mission, as well as community partners in promoting physical activity and exercise for all individuals. Resources are available, comparable to an IEP, for students with disabilities that may impact participation in the course. A faculty member is assigned 0.5 FTE to coordinate the physical activity elective program. It is expected and necessary to troubleshoot, early and often particularly for the newcomers to higher education. Whether based on the logistics of teaching such as (a) student progress reports, (b) utilization of the campus LMS, (c) submitting grades, (d) course evaluations/satisfaction surveys, or (e) responding to various campus requests, IUPUI recognizes the challenge to cover each nuance when the initial goal is for instructors to begin teaching quickly and effectively, therefore ongoing support is essential. Finally, the department recently developed a system to reward continuing part-time faculty, rated effective and higher, as a way to earn professional development funds to support their professional journey.

Similar to IUPUI, the Physical Activity and Wellness Program (PAWP) at Auburn University revolves in a perpetual cycle of matching qualified instructors with course offerings. The intricate synchronicity of instructors and content depends on student demand, facilities, 
expertise, and scheduling, not only to fit within an academic day, but also around the varied responsibilities of the available instructors. Being a large program offering 265 courses annually, this delicate balancing act with the ultimate goal of effective instruction can be particularly challenging. The reality is these challenges result in multiple sections of high demand canned courses (e.g., Active Auburn) constituting 37\% of PAWP enrollment, predominantly online, completely prepared in advance by the coordinator, and requiring minimal training. Although at first glance, these courses may appear to lack rigor, to the contrary, they are extremely structured with detailed physical activity and accountability criteria, and most importantly a shorter learning curve for instructors. Additionally of note, these courses are a significant revenue generator for the School of Kinesiology at AU, yielding over $\$ 400,000$ annually upon initial analysis of Active Auburn alone (Brock et al., 2016).

Beyond online multi-section offerings, the PAWP includes sport and fitness-based courses that depend on specific instructor expertise (Taekwondo, scuba, self-defense, yoga), taught by community professionals/business owners and graduate teaching assistants (GTA) with specialized content experience. Graduate students are polled to determine expertise, yet it is important to note GTA turnover is frequent and obviously imminent due to degree completion, which factors into course offerings and more importantly support and training. While recruitment is not a major obstacle at $\mathrm{AU}$, supporting and maintaining effective instruction with frequent turnover can be a substantial challenge.

In outlining the approach to supporting effective instructional practices in the PAWP at AU, it is important to identify two influential factors that guide time and efforts. First, most of the 11 community instructors have been teaching for the School of Kinesiology for $10+$ years and have established a proven record of excellence. These experts stay abreast of the latest 
techniques and implement new AU policies and procedures with minimal training, as the success of their business ownership is influenced by effective course instruction (e.g., golf, scuba, and bowling). Community instructors are evaluated by students and the School director, and the PAWP coordinator provides support as needed. Second, the majority of instructors are from a plentiful pool of GTAs $(N=40)$ who have much less teaching experience, if any, and need more training, support, and accountability. Hence, most resources are geared toward GTAs.

Through experience, the PAWP at Auburn has learned when training GTAs, information dispersed over a longer period of time and at teachable moments is most effective. New GTAs begin completing training modules several months in advance of arriving on campus. The modules include videos and quizzes related to topics such as accommodations, campus safety, first aid/CPR, FERPA, academic honesty, and the PAWP handbook (Brock et al., 2018). GTAs self-pace to avoid inundation of excessive information, and receive specific information related to assigned courses (e.g., syllabi, course outline) to begin preparing daily content. Upon arriving to campus, GTAs participate in orientations conducted by the School of Kinesiology and the Biggio Center for Teaching Excellence, a program for AU faculty and graduate students desiring to improve teaching. GTAs enroll in a one-credit hour teaching seminar course and are evaluated by the PAWP coordinator each semester, as well as by students via course evaluations. The most essential component to the approach to support effective instruction is the addition of a $1.0 \mathrm{FTE}$ PAWP administrative coordinator. This adds the piece of the puzzle desperately needed to provide training, accountability, consistent course delivery, and a constant daily liaison to GTAs, particularly during teachable moments most critical to supporting effective instruction.

\section{Future Advocacy \& Opportunities}


While it is recognized context varies across institutions, IPAPs must critically examine local opportunities to support and strengthen the institutional value of the IPAP. Stapleton et al. (2017) suggested programs consider (a) adopting a public health perspective, (b) applying theoretical models as a framework for program development, (c) focusing on meaningful learner engagement, and (d) employing learner-centered instructional approaches. This paper briefly shares some practices supporting learner-centered instructional approaches and examples of providing quality IPAP curriculum and courses while supporting effective instruction. To expand upon the theme of sharing and supporting best practices to support and sustain high-quality effective IPAPs, an overview is provided of advocacy and opportunities shared through two of the respective author institutions.

As IPAPs consider factors associated with declining enrollment patterns along with identifying qualified instructors, programs are encouraged to explore networking and partnerships. In particular, GVSU has strengthened partnerships with Campus Recreation and has developed a new 2-credit hybrid FIT course to be piloted in the 2020-2021 academic year. The course blends lifetime health and fitness content with group exercise courses delivered through Campus Recreation. Students have the flexibility of selecting and exploring a range of group exercise courses that fit their schedule. Instructional content is delivered face-to-face and online. The course emphasizes social and emotional wellbeing with physical activity participation and targets incoming students and students with less than 60 credits. In addition to partnerships with Campus Recreation, programs are highly encouraged to consider strengthening partnerships and networks with Student Affairs, University Residence Life, Disability Support Resources, Divisions of Inclusion and Equity, etc. Finding opportunities to promote, support, and 
engage IPAPs with other campus entities is essential for sustaining programs in times of economic uncertainty.

Another area of opportunity to consider is the role of IPAP courses as degree electives or general education/core curricula requirements (Cardinal et al., 2012; Kim \& Cardinal, 2019). GVSU recently revised and expanded the existing content in a 2-credit hour personal health and wellness course to a 3-credit personal health and wellness course. With an increase in credits and adoption of new content related to social and behavioral sciences, the course is an elective within the university's general education curriculum within the Social and Behavioral Science category. Expanding beyond offering elective courses within general education or core requirements, IPAPs should vigorously consider offering courses as degree requirements (Kim \& Cardinal, 2019). Consistent with a public health approach, required courses extend the reach of physical activity and wellness to all students. At UIndy, a 1-credit hour graded wellness and fitness course is required for all undergraduate students. The wellness and fitness course consists of approximately 50\% physical activity and 50\% didactic content with the classroom activities focusing on multi-dimensions of wellness. The course is offered in both face-to-face and online formats. In addition, the university offers physical activity courses which are both elective credits to all students and required in a unique concentration, such as the Healthy Diploma ${ }^{\mathrm{TM}}$. UIndy's innovative Healthy Diploma ${ }^{\mathrm{TM}}$ (Hicks \& Schmidt, 2016) is an example of innovative programming promoting IPAPs. The Heathy Diploma has been active for 11 years and has demonstrated an $80 \%$ retention rate. The mission of the Healthy Diploma ${ }^{\mathrm{TM}}$ program is dedicated to promoting healthy behaviors and using the program as a marketing strategy to potential employers. The program, available to all students regardless of academic major, incorporates physical activity, education, wellness coaching, and assessment, to provide 
experiential opportunities for students to participate in regular physical activity, gain knowledge and self-awareness thus achieving meaningful student engagement (Stapleton et al., 2017). Similar in concept to an honors diploma, this concentration requires 15 credit hours of health and kinesiology courses. This experience provides healthier students as employees with better performance and contributions in the workplace, as associated with a healthy lifestyle.

Departments in higher education are increasingly asked to do more while also competing for limited resources. Aligning with Stapelton's et al. (2017) suggestion of adopting a public health perspective and servicing the institution, UIndy created the innovative BeWell program, to manage resource challenges and deliver an employee wellness program. Based on the American College of Health Standards of Practice for Health Promotion in Higher Education (2019), UIndy's coordinated worksite wellness campus initiative engages faculty, staff, students, and community partners in the provision of a campus culture of wellness. The grassroots program consolidates and expands previously isolated academic and employee campus wellness initiatives into a coordinated effort. A unique program characteristic includes engaging students and faculty through applied, coordinated learning experiences, and increased interprofessional collaboration among academic units. Faculty experts from various academic units (public health, occupational therapy, physical therapy, exercise science, behavioral health, business, music, art, and nursing) are recruited to support BeWell programming. BeWell increases department awareness, offers experiential learning experiences for students, and provides faculty and staff with health and wellness support. These efforts promote healthy lifestyle choices to foster a productive work environment and educational space.

Exploring links and partnerships, developing innovative programs, examining the value of required vs. elective courses, are a few areas of advocacy and opportunity to consider. 
Ensuring quality programming and supporting effective instructional practices are essential for sustaining IPAPs. While continuing to advocate for IPAP programs, establishing links between physical activity and wellness with student success will be key (Kim \& Cardinal, 2019). The reach of IPAPs extend beyond the physical and socioemotional wellbeing of students. Providing evidence of IPAP participation and links with student success markers such as retention, graduation, and academic performance will further strengthen physical activity and wellness education for college students.

\section{Conclusion}

For decades, IPAPs, also identified as basic, general physical education, physical activity and wellness programs, have played a crucial role in the delivery of health, wellness, physical activity, and fitness content to college students. The authors hope that lessons learned from time as IPAPs administrators outlined in this paper assist others in endeavors to bring innovation, collaboration, advocacy, sustainability, and creativity to the broadening mission of IPAPs. As with most academic programs, challenges and opportunities, internal and external to a given institution, routinely present themselves that impact the scope, focus, curriculum, and mission of IPAPs. IPAP leadership's response to these challenges and opportunities must be contextualized and aligned with the overall needs of a respective academic program, institution, and constituency served. The focus for IPAPs has and should always remain supporting the development of students' lifelong engagement in activities that emphasize enhanced fitness, wellness, and the ability to be physically active. 


\section{References}

Ansari, W. E., Oskrochi, R., \& Haghgoo, G. (2014). Are students' symptoms and health complaints associated with perceived stress at university? Perspectives from the United Kingdom and Egypt. International Journal of Environmental Research and Public Health, 11(10), 9981-10002. https://doi.org/10.3390/ijerph111009981

Baghurst, T., \& Kelley, B. C. (2014). An examination of stress in college students over the course of a semester. Health Promotion Practice, 15(3), 438-447. https://doi.org/10.1177\%2F1524839913510316

Brock, S. J., Russell, J. A., Cosgrove, B., \& Richards, J. (2018). Administrative strategies for delivering high-quality instruction in a university-based physical activity and wellness program. Kinesiology Review, 7(4), 345-349. https://doi.org/10.1123/kr.2018-0040

Brock, S. J., Wadsworth, D., Hollett, N., \& Rudisill, M. (2016). Using Movband technology to support online learning: An effective approach to maximizing resources in kinesiology. Kinesiology Review, 5(4), 289-294. https://doi.org/10.1123/kr.2016-0028

Cardinal, B. J. (2017). Quality college and university instructional physical activity programs contribute to mens sana in corpore sano,"the good life," and healthy societies. Quest, 69(4), 531-541. https://doi.org/10.1080/00336297.2017.1320295

Cardinal, B. J., \& Kim, M. (2017). Why do university students enroll in physical activity education courses? Differential affects of required versus elective institutional policies. International Journal of Sports and Physical Education, 3(3) 16-26. http://dx.doi.org/10.20431/2454-6380.0303003

Cardinal, B. J., Sorensen, S., \& Cardinal, M. K. (2012). Historical perspective and current status of the physical education graduation requirement at American 4-year colleges and 
universities. Research Quarterly for Exercise and Sport, 83(4), 503-512. https://doi.org/10.1080/02701367.2012.10599139

Casebolt, K., Bland, H., Russell, J., \& Melton, B. (2015). Student perceptions of instructional physical activity programs in higher education and their intention to engage in lifelong physical activity. Pennsylvania Journal of Health, Physical Education, Recreation and Dance, 85, $29-33$.

Crawford, S. Z., Greenwell, T. C., \& Andrew, D. P. (2007). Exploring the relationship between perceptions of quality in basic instruction programs and repeat participation. Physical Educator, 64(2), 65.

Hicks, L., \& Schmidt, D. (2016). The Healthy Diploma ${ }^{\mathrm{TM}}$ and Healthy Titans: Two innovative campus programs for progressive student, profession, and community outcomes. Kinesiology Review, 5(4), 269-275. https://doi.org/10.1123/kr.2016-0026

Kim, M. S., \& Cardinal, B. J. (2019). Differences in university students' motivation between a required and an elective physical activity education policy. Journal of American College Health, 67(3), 207-214. https://doi.org/10.1080/07448481.2018.1469501

Kimmel, K. M., \& Fairchild, J. L. (2017). A full-time dilemma: Examining the experiences of part-time faculty. Journal of Effective Teaching, 17(1), 52-65.

Langdon, J. L., \& Wittenberg, M. (2019). Need supportive instructor training: Perspectives from graduate teaching assistants in a college/university physical activity program. Physical Education and Sport Pedagogy, 24(1), 16-30.

Melton, B., \& Burdette, T. (2011). Utilizing technology to improve the administration of instructional physical activity programs in higher education. Journal of Physical 
Education, Recreation \& Dance, 82(4), 27-32.

https://doi.org/10.1080/07303084.2011.10598611

Melton, B. F., Moore, C. S., \& Hoffman, B. (2016). Strategies for college and university instructional physical activity program (IPAP) directors. International Journal of Higher Education, 5(1), 292-299. http://dx.doi.org/10.5430/ijhe.v5n1p292

National Association of Sport and Physical Education. (2009). Appropriate instructional practice guidelines for higher education physical activity programs (2nd ed.). Reston, VA: author

Russell, J. (2010). Instructional concerns of kinesiology basic instruction program graduate teaching assistants. Studies in Graduate and Professional Student Development, 13, 2342.

Russell, J. (2011). Graduate teaching-assistant development in college and university instructional physical activity programs (Featured section: College and university instructional physical activity programs). Journal of Health, Physical Education, Recreation and Dance, 82(4), 22-26. https://doi.org/10.1080/07303084.2011.10598610

Russell, J., Wadsworth, D., Hastie, P., \& Rudisill, M. (2014). Incorporating e-learning to enhance instruction and student experiences in collegiate physical activity courses. Kinesiology Review, 3(4), 247-252. https://doi.org/10.1123/kr.2014-0066

Santisteban, L., \& Egues, A. L. (2014, July). Cultivating adjunct faculty: Strategies beyond orientation. In Nursing Forum (Vol. 49, No. 3, pp. 152-158). https://doi.org/10.1111/nuf.12106

Stapleton, D. T., Taliaferro, A. R., \& Bulger, S. M. (2017). Teaching an old dog new tricks: Past, present, and future priorities for higher education physical activity programs. Quest, 69(3), 401-418. https://doi.org/10.1080/00336297.2016.1256825 
Table 1

Instructional Physical Activity Program Characteristics by University

\begin{tabular}{|c|c|c|c|c|c|c|c|}
\hline INSTITUTION & $\begin{array}{c}\text { CARNEGIE } \\
\text { CLASSIFICATION }\end{array}$ & $\begin{array}{l}\text { REQ'D/ } \\
\text { GENED }\end{array}$ & $\begin{array}{c}\text { CRHRS / } \\
19 / 20\end{array}$ & $\begin{array}{l}\text { \%DEPT } \\
\text { CRHRS }\end{array}$ & $\begin{array}{l}\text { COORD/ } \\
\text { SUPV(FTE) }\end{array}$ & $\begin{array}{l}\text { SHARE } \\
\text { FACILITY }\end{array}$ & $\begin{array}{c}\% \mathrm{FTE} \\
\text { FACULTY }\end{array}$ \\
\hline$A U$ & $\begin{array}{c}\text { (R1) Doctoral } \\
\text { Universities: } \\
\text { Very High } \\
\text { Research } \\
\text { Activity }\end{array}$ & No & 16,582 & $\sim 48$ & $\begin{array}{c}\text { Yes } \\
(1.0)\end{array}$ & No & $\sim 4$ \\
\hline GVSU & $\begin{array}{c}\text { (M1) Master's } \\
\text { Colleges \& } \\
\text { Univ: Larger } \\
\text { Programs }\end{array}$ & No & 4,232 & $\sim 19$ & $\begin{array}{l}\text { Yes } \\
(0.5)\end{array}$ & Yes & 10-12 \\
\hline IUPUI & $\begin{array}{l}\text { (R2) Doctoral } \\
\text { Universities: } \\
\text { High Research } \\
\text { Activity }\end{array}$ & No & 1,547 & $\sim 10$ & $\begin{array}{l}\text { Yes } \\
(0.5)\end{array}$ & Yes & $\sim 3$ \\
\hline UINDY & $\begin{array}{c}\text { (D/PU) } \\
\text { Doctoral/ } \\
\text { Professional } \\
\text { Universities }\end{array}$ & Yes & 691 & $\sim 10$ & $\begin{array}{l}\text { Yes } \\
(.21)\end{array}$ & Yes & $\sim 6$ \\
\hline
\end{tabular}

Note. \% DEPT CRHRS indicates the percentage IPAP course credit hours in relation to total departmental credit hours. \% FTE Faculty indicates the percentage of IPAP courses taught by full-time faculty. 